Burch, G. E., and De Pasquale, N. P. (1962). Circulat, Res., 10, 105. Conrad, M. C., and Green, H. D. (1964). Circulation, 29, 847. Cooper, K. E., Edholm, O. G., and Mottram, R. F. (1955). F. Physiol. (Lond.), 128, 258.

Davis, M. T., and Greene, N. M. (1959). F. appl. Physiol., 14, 961.

de Crinis, K., Redisch, W., Antonio, A., Bogdanovitz, A., and Steele, J. M. (1959). Circulation, 19, 583.

de Takats, G. (1958). Arch. Surg., 77, 655.

Edwards, E. A., and Crane, C. (1961). f. Amer. med. Ass., 175, 677.

Folkow, B. (1956). In Hypotensive Drugs, edited by M. Harington. Pergamon, London.

Freeman, N. E. (1935). Amer. F. Physiol., 113, 384.

Leeds, F. H., and Gardner, R. E. (1947). Ann. Surg., 126, 873. Gairns, F. W., Garven, H .S. D., and Smith, G. (1960). Scot. med. F., $5,382$.

Gillespie, J. A. (1960a). Brit. med. F., 2, 1640.

Hill (1960b). Lancet, $1,891$.

Hill, A. V. L., Lyall, I. G., and Barnett, A. J. (1962). Med. F. Aust., 2,901 .

Holopainen, Y. V. O. (1963). Acta chir. scand., Suppl. No. 311.

Husni, E. A., and Simeone, F. A. (1957). Arch. Surg., 75, 530.

Hyman, C., and Winsor, T. (1959). Amer. 7. Cardiol., 4, 566

Knox, W. G. (1959). Ann. Surg., i49, 539.

Löfving, B., and Mellander, S. (1956). Acta physiol. scand., 37, 134
Lynn, R. B., and Barcroft, H. (1950). Lancet, 1, 1105.

McPherson, A., and Kessel, A. W. L. (1956). Ibid., 1, 713.

Megibow, R. S., Pollack, H., Megibow, S. J., Bookman, J. J., and Osserman, K. (1949). Amer. Heart J., 38, 468.

Mendlowitz, M. (1951). Circulation, 3, 694.

Grossman, E. B., and Alpert, S.' (1953). Amer. F. Med., 15, 316.

Myers, K. A. (1964). Angiology, 15, 293.

and Irvine, W. T. (1966). Brit. med. F., 1, 879.

Pickering, G. W. (1933). Heart, 16, 115.

Ross, J. P. (1953). Ann. roy. Coll.' Surg. Engl., 13, 356

Smithwick, R. H. (1957). Surgery, 42, 415.

Soila, P., Berglund, K., Lagergren, C., and Vainio, K. (1959). Transactions Ninth Inlernational Congress of Radiology, $1,248$.

Stein, I. D. (1956). Angiology, 7, 432.

Taylor, G. W., and Calo, A. R. (1962). Brit. med. F., 1, 507.

Thimmig, R. F., Smith, M. B., and Sullivan, J. M. (1958). Surg. Clin. N. Amer., 38, 1081

Tice, D. A., Reed, G E., Messina, E. J., Clemente, E., and Redisch, Arch. Surg., 87, 461.

Walker, A. J., Lynn, R. B., and Barcroft, H. (1950). St. Thom. Hosp. Rep., 6, 18.

Whitney, R. J. (1953). 7. Physiol. (Lond.), 121, 1.

Wright, G. W., and Phelps, K. (1940). Ұ. clin. Invest., 19, 273.

\title{
Clinical Features of Autosomal Dominant and Sex-linked Ichthyosis in an English Population*
}

\author{
R. S. WELLS, $\dagger$ M.D., M.R.C.P., M.R.C.P.ED., D.C.H. ; C. B. KERR, $†$ M.B., B.S.
}

Brit. med. F., 1966, 1, 947-950

It is generally believed that ichthyosis is a relatively common hereditary disorder, though there is little information on its actual prevalence. Rare varieties have been adequately defined in descriptive terms, but difficulties have arisen over the characteristics of frequently encountered forms. In order to obtain information on prevalence, clinical features, and genetics of ichthyosis, a survey was undertaken in the five counties surrounding Oxford. Through studying clinical features of ichthyosis in families where the mode of inheritance could be defined it was possible to separate two distinct varieties due to either autosomal dominant or to sex-linked genes. As these two conditions account for over $95 \%$ of all cases of ichthyosis, the characteristic clinical features of each variety are emphasized. A genetical classification of ichthyosis is given in Table $I$.

TABLE I.-Genetical Classification of Ichthyosis

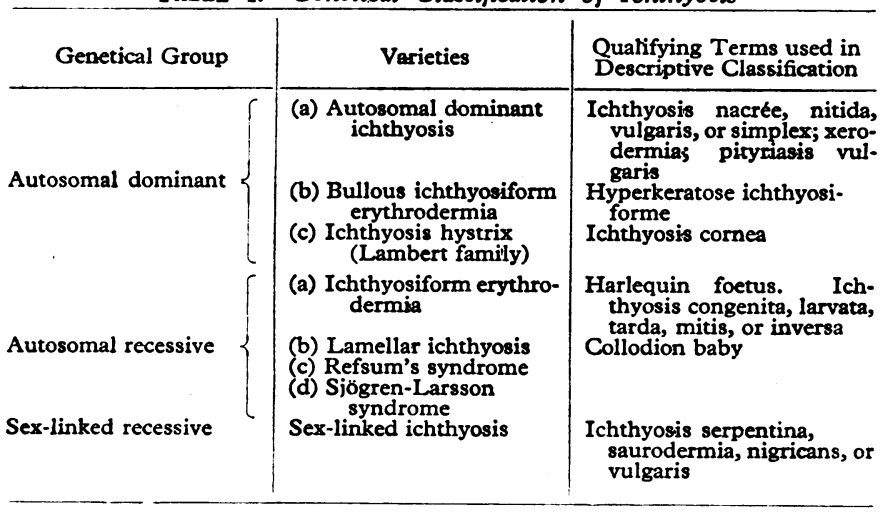

\section{Historical Background}

Although known to Avicenna as "albarras nigra" and also described in the fourteenth century by the Chinese (Chan, 1950), ichthyosis was first clearly described in the English literature by Willan in 1808. Many different varieties were subsequently reported, but most authors recognized two major categories. One was characterized by small, fine scales with "a greyish, silvery and glossy" appearance (Erasmus Wilson, 1857), previously likened by Alibert (1806) to mother-of-pearl (ichthyosis nacrée). In the other category the scales were larger, "dark-coloured, greyish green, brown, or black" and more firmly fixed to the underlying skin (Hebra and Kaposi, 1874). Radcliffe Crocker (1896) gave a detailed account of the clinical features and in contrast to most previous reviewers noted that "fanciful names" merely led to confusion, and were to be avoided. Cockayne (1933) was the first to use a genetical classification, but neither he nor, more recently, Greither (1964) distinguished between the clinical characteristics of varieties with differing inheritance. Touraine (1958) was forced to construct many categories and subcategories to accommodate all recorded types of ichthyosis in a descriptive classification. Genetical and clinical evidence on which rare forms are classified as distinct entities in Table I is reviewed in detail elsewhere (Wells and Kerr, 1965).

\section{Present Investigation}

During 1962-4 persons with ichthyosis living in Oxfordshire, Northamptonshire, Buckinghamshire, Berkshire, and Wiltshire were ascertained from general practitioners, consultant dermatologists, hospital records, and school medical officers of health. An additional family with sex-linked ichthyosis was studied in Northern Ireland. Data for genetical and clinical analysis were sought from the families of 288 index cases and over 1,100 relatives were examined. Co-operation was excellent, as less than $1 \%$ of those approached refused to take part in the investigation.

* This paper represents part of a thesis by one of us (R.S. W.) accepted for the M.D of the University of London.

† From the Population Genetics Research Unit, Oxford. Sydney. 
Clinical information and personal details were recorded on a standard form for subsequent transcription to cards for machine sorting of data. Some 600 colour photographs were taken with a Retinette $1 \mathrm{~B}$ camera. These proved of great value in providing an objective record for comparative purposes. Skin sections from 27 patients were obtained by punch biopsy for histological comparison with normal skin sections. Colour vision was tested and blood was taken from suitable families containing males with sex-linked ichthyosis for Xg bloodgrouping (by Drs. Race and Sanger) in order to provide information on $\mathrm{X}$ chromosomal gene linkage.

\section{Results}

From all sources 375 individuals were ascertained as affected by ichthyosis, and the diagnosis was confirmed in 288 of these. Investigations of relatives yielded a further 155 affected persons. A total of 389 persons were fully examined, and these formed the group for clinical investigation. Two instances of acquired ichthyosis associated with generalized disease were encountered, these not being included in this report. One hundred and sixty-nine affected individuals came from families where ichthyosis was inherited as an autosomal dominant trait, and for another 81 patients (all males) the inheritance was sex-linked. Eight persons had well-defined varieties of ichthyosis resulting from homozygosity for autosomal recessive genes; seven of these from four families had ichthyosiform erythrodermia and one had lamellar ichthyosis.

Clinical characteristics of the two major types of ichthyosis classified on a genetical basis are listed in Table II, and the formal analysis of family data confirmed that one variety was caused by a sex-linked recessive gene (Kerr and Wells, 1965). Histological results showing clear differences between sexlinked and autosomal dominant ichthyosis will be briefly described and reported in full elsewhere (Wells and Kerr, 1966). Conclusions on linkage have been described in detail (Kerr, Wells, and Sanger, 1964). There was evidence that the genes for sex-linked ichthyosis and the $\mathrm{Xg}$ blood groups were within measurable distance of each other on the $\mathrm{X}$ chromosome, but insufficient information was obtained to study linkage with colour-blindness loci.

TABle II.-Comparison of Clinical Characteristics in Sex-linked and
Autosomal Dominant Ichthyosis

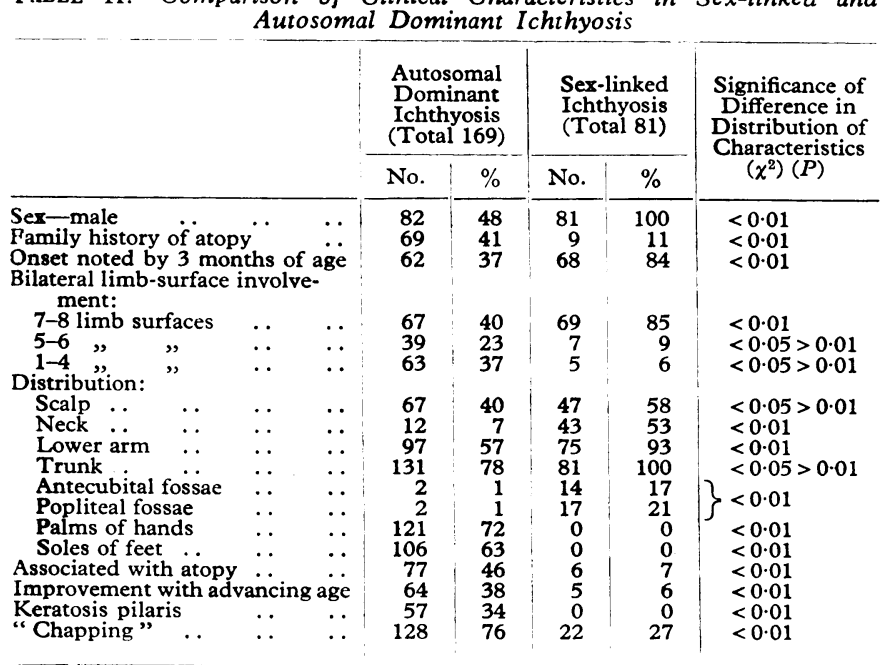

\section{Prevalence}

Case-finding was undertaken most extensively in Berkshire (including Reading County Borough), where general practitioners provided information on ichthyosis in their practices on three different occasions, records kept by consultants and in dermatology clinics were thoroughly searched, and 6,051 schoolchildren were specifically examined for ichthyosis. Therefore estimations on prevalence are here confined to Berkshire.

The observed frequency of all types of ichthyosis was 1 per 3,665 persons. For sex-linked ichthyosis the incidence was 1 per 13,500 (or 1 per 6,190 males). The observed frequency of autosomal dominant ichthyosis, 1 per 5,300 persons, is only a minimal estimate, and the actual frequency is certainly much higher, as 24 of 6,051 schoolchildren were affected-a frequency of 1 per 250 .

Autosomal recessive ichthyosis was detected with a trait frequency of approximately 1 per 300,000 persons in Berkshire.

\section{Comparison of Characteristics in Sex-linked Ichthyosis and Autosomal Dominant Ichthyosis}

Sex.-Sex-linked ichthyosis was found only in males; no demonstrable gene effect was detected in 61 females who from pedigree evidence were heterozygous for the gene. Males and females were equally affected with the autosomal dominant type of ichthyosis.

Age of Onset.-For cases where reliable information could be obtained, dry scaling skin was noted at birth only in the sex-linked group (17\%). Several of these had sheets of scales, giving an appearance often described as "collodion babies." By three months of age $84 \%$ had obvious ichthyosis as compared with $40 \%$ of the autosomal dominant group. Some of the latter were not affected until over 1 year of age.

Associated with Manifestations of Atopy.-Eczema, hayfever, or asthma was frequently experienced either singly or in combination by relatives of index cases with autosomal dominant ichthyosis. Of the latter, $41 \%$ had at least one relative with atopic manifestations. By contrast only $11 \%$ of index cases with sex-linked ichthyosis had an atopic relative. Nearly half of the autosomal dominant patients experienced some atopic symptoms as compared with $7 \%$ with sex-linked ichthyosis and $9 \%$ of a control group of 350 persons attending a wart clinic (H. T. Calvert, personal communication, 1963).

Severity.-A measure of severity was obtained by recording the number of affected limb surfaces. The most extensive involvement of the body surface was found in males with sex-linked ichthyosis aged more than 20 years. Sixty per cent of the autosomal dominant patients were only mildly or moderately affected.

Scalp.-The large thick yellow scales commonly found in sex-linked ichthyosis (particularly in patients aged less than 20) are quite different from fine "dandruff-like" scales typical of the autosomal dominant variety. No relevant abnormality of the hair was noted.

Face.-A different distribution of ichthyosis was noted in the younger members of each group. The forehead and cheeks were typically involved in autosomal dominant ichthyosis, whereas the ears and the side of the face immediately in front of the ears were commonly affected in the sex-linked group. No relevant ocular abnormalities were detected in affected persons.

Neck.-An almost pathognomonic feature of sex-linked ichthyosis is marked scaling on the neck. This was noted in $74 \%$ of those aged less than 20 years; the typically dark colour of scales in this region has often been described as "ichthyosis nigricans." Scaling also occurred on the neck of some young patients with autosomal dominant ichthyosis, but very seldom assumed the "dirty" appearance of the former group.

Trunk and Limbs.-As shown in Table II, these areas are most extensively involved in sex-linked ichthyosis. In this group the trunk was invariably affected and scaling was usually 
more pronounced on the abdomen than on the back, in contrast to the other variety, where the reverse situation was found.

Axillae, Antecubital and Popliteal Fossae.-Autosomal dominant ichthyosis did not involve the axillae, and only very rarely other fossae. Several sex-linked patients were affected in these areas, but there was a distinct relationship with age. Ichthyosis of the axillae and antecubital fossae was generally found in young patients and diminished with advancing years, whereas involvement of the popliteal fossae developed in later life.

Elbows, Knees, and Heels.-Involvement of these areas appeared to be part of the general process in sex-linked ichthyosis but not in the other variety, where the affected skin was often strikingly different from elsewhere and consisted of localized and sometimes shining patches of hyperkeratosis.

Palms and Soles.-Increased palmar markings were commonly found in autosomal dominant ichthyosis, often in association with atopic eczema. Similar plantar patterns were usually present in the same patients. These features were never detected in any patient w:th sex-linked ichthyosis. There were no relevant abnormalities of the nails.

Keratosis Pilaris and Chapping.-Keratosis pilaris was confined to patients with autosomal dominant ichthyosis and commonly found in the younger age groups. Because "chapping" is such a vague term, and difficult to define, patients were merely asked if they suffered from chapping of the hands and feet. It was found that a positive answer generally referred to painful, often infected, fissures of the hands or heels, and $76 \%$ of autosomal dominant patients replied in the affirmative, as compared with $27 \%$ of the sex-linked group. The latter frequency was close to that found for chapping in the control group-that is, $29 \%$.

Scales.-By examining scales attached to the patients or collected after being shed it was found that autosomal dominant ichthyosis was characterized by small fine white scales with the consistency of bran. Typical scales from the sex-linked group were much larger (diameter greater than $4 \mathrm{~mm}$.) and of a colour varying from yellow to dark brown. A seasonal variation in shedding of scales was reported by some patients with sex-linked ichthyosis. Usually termed "moulting," the fall of scales was heaviest in the autumn, and several severely affected patients noted a further moult during the spring.

\section{Effect of Age, Weather, and Treatment}

Thirty-eight per cent. of those with autosomal dominant ichthyosis were convinced that the extent and degree of ichthyosis had improved as they grew older. This was confirmed by studying photographs of patients in different age groups and through encountering relatives of affected persons for whom there was an objective record of ichthyosis at an earlier age, although no sign of this could be detected on physical examination at the present time. By contrast, sex-linked ichthyosis appeared to become more marked with advancing age. Here again, photographic comparison of different age groups was in agreement, though it was noted that scaling on the face, scalp, and neck was significantly less in adults than in children and adolescents.

Warm weather produced an often remarkable diminution in scaling in both groups, the effect being more dramatic in severely affected patients with sex-linked ichthyosis. However, signs of ichthyosis were always present in the latter group under such conditions, whereas a warm climate could induce an apparently complete remission in some autosomal dominant patients.

The effect of applying oils and ointments is difficult to evaluate, but there is little doubt that diligent and consistent treatment will completely control scaling in many patients with autosomal dominant ichthyosis and a few babies with the sex-linked variety. After infancy no form of treatment was of more than transient value in sex-linked ichthyosis and most adult patients had abandoned any attempt at therapy.

\section{Histological Features}

Comparison of sections from 12 patients with autosomal dominant ichthyosis, 15 males with sex-linked ichthyosis, and 12 normal persons has been discussed in detail elsewhere (Wells and Kerr, 1966). Consistently different appearances were noted for each type of ichthyosis, notably in the width of the stratum granulosum, which was increased in the sex-linked group and diminished in the other. Definite acanthosis of the stratum mucosum and prominence of the rete ridges was confined to sex-linked ichthyosis, whereas follicular plugging was noted only in the autosomal group.

\section{Autosomal Recessive Ichthyosis}

The seven patients with ichthyosiform erythrodermia and one with lamellar ichthyosis had typical features of these conditions. The clinical appearances and natural history of these rare forms are well known, and are quite distinct from those in sex-linked or autosomal dominant ichthyosis.

\section{Discussion}

No difference between the clinical features of common types of ichthyosis has been previously noted, but the results of the present survey show that such a distinction is indeed possible. The distribution of characteristics in each genetical group provided criteria for classifying the type of ichthyosis in 139 affected persons, who were either sporadic cases or came from families from which was gathered insufficient information to define a mode of inheritance. In this way a further 19 males were classified as affected with sex-linked ichthyosis. The remainder had features consistent with autosomal dominant ichthyosis. There is little doubt that ichthyosis is more prevalent among the population than is suggested by an observed frequency for all cases in Berkshire of 1 per 3,665 persons. There is an obvious deficiency of those with mild ichthyosis, who rarely seek medical advice. Lomholt (1963) conducted a somewhat more extensive survey of skin diseases on the Faroe Islands, visiting a number of households. $\mathrm{He}$ gave the overall frequency of ichthyosis as 1.1 per 1,000 persons.

The relatively high frequency of ichthyosis due to a recessive sex-linked gene was quite unexpected, as fewer than 30 pedigrees illustrating this mode of inheritance had been reported since the first description by Rayer in 1835 . Ascertainment of sex-linked patients was presumably more complete in view of the more severe skin involvement. However, less than half the affected adults ascertained through an index case had ever consulted a doctor about their skin. On the other hand, all those born since the inception of the National Health Service had seen a general practitioner, and often a consultant dermatologist, on at least one occasion. Although there is no physical morbidity associated with common varieties, the " dirty" appearance of affected skin in sex-linked ichthyosis is universally distressing to patients. In one family an affected male was alleged to have committed suicide while depressed over his appearance. Lesions in rare autosomal types are also socially embarrasing, but facial scaling in females with the common autosomal dominant ichthyosis can usually be concealed with cosmetics. Patients with the latter variety can be informed that their skin disorder usually improves with advancing years, the converse situation being noted in sexlinked ichthyosis.

The frequent association of autosomal dominant ichthyosis with manifestations of atopy cannot be readily explained at 
present. Clinical and histological features in patients with or without atopy were compared, but no evidence was obtained that would shed light on this problem.

Requests for advice on the probability of conceiving affected males may be made by female members of families with sex-linked ichthyosis. As the carrier state cannot be detected on clinical and histological grounds, and the gene is not closely linked with the Xg blood-group locus, genetical predictions can be based only on conventional Mendelian analysis.

\section{Summary}

Three hundred and eighty-nine persons with ichthyosis ascertained in a population survey were examined. Through classifying patients by mode of inheritance the clinical and histological characteristics of common varieties of ichthyosis due to autosomal dominant or sex-linked genes were defined. Comparison of characteristics showed that separation of the two groups was possible. Apart from differences in distribution of ichthyosis on the body surfaces, males with sex-linked ichthyosis were more extensively affected and scaling did not improve with advancing years. By contrast, autosomal dominant ichthyosis was a milder condition with less prominent scales, and was frequently associated with manifestations of atopy, keratosis pilaris, and chapping. The appearance of the latter variety corresponds to the previous descriptive terms ichthyosis nacrée or nitida and of the former variety to ichthyosis saurodermia or serpentina.
The population frequency of ichthyosis was discussed and an unexpectedly high prevalence of sex-linked ichthyosis noted in Berkshire.

We wish to thank Dr. A. C. Stevenson for suggesting the investigation and for hetp and criticism while it was beng completed, Dr. A. H. T. Robb-Smith for providing histological facilities, Dr. R. R. Race and Dr. R. Sanger for Xg blood-grouping, and all the consultant dermatologists, general practitioners, and school medical officers of health in the Oxford Regional Hospital Board area for referring patients. In addition, Miss K. Major and Miss R. Mason provided indispensable help when visiting families and during all stages of the investigation.

\section{REFERENCES}

Alibert, J. L. (1806). Descriptions des maladies de la peau observées d̀ l'hôital Saint-Louis. Barrois l'ainé, Paris.

Chan, E. (1950). Chin. med. F., 68, 378.

Cockayne, E. A. (1933). Inherited Abnormalities of the Skin and its Appendages. Oxford University Press, London.

Greither, A. (1964). Dermatologica (Basel), 128, 464. Hebra, F., and Kaposi, M. (1874). On Diseases of the Skin, vol. 3, London.

Kerr, C. B., and Wells, R. S. (1965). Ann. hum. Genet., 29, 33.

L and Sanger, R. (1964). Lancet, 2, 1369.

Lomholt, G. (1963). Psoriasis, p. 204. Gad, Copenhagen

Radcliffe Crocker, H. (1896). Atlas of the Diseases of the Skin. Young, Edinburgh and London.

Rayer, P. (1835). A Theoretical and Practical Treatise on the Diseases of the Skin. Baillière, London.

Touraine, A. (1958). Ann. Derm. Syph. (Paris), 85, 257.

Wells, R. S., and Kerr, C. B. (1965). Arch. Derm., 92, 1

(1966). F. invest. Derm. In press.

Willan, R. (1808). On Cutaneous Diseases. Johnson, London. Wilson, Erasmus (1857). On Diseases of the Skin. Churchill, London.

\title{
Treatment of "Refractory Obesity" with a Diet of Five Meals a Day
}

\author{
J. F. MUNRO,* M.B., CH.B., M.R.C.P.ED. ; D. A. SEATON,* M.D., M.R.C.P.ED., M.R.C.P.GLASG. \\ L. J. P. DUNCAN,* M.B., B.SC., F.R.C.P.ED.
}

Brit. med. F., 1966, 1, 950-952

Though a wide variety of dietary regimens and many drugs said to have appetite-reducing properties have been recommended for the treatment of obesity, they have all too often been ineffective when subjected to critical study. However, attention has recently been drawn to the effects on weight of varying feeding habits, and Hollifield and Parson (1962) have shown that rats given infrequent access to food become heavier than those allowed unrestricted "nibbling." Similarly, the incidence of excess weight in elderly Czechoslovakian men has been reported to be greater in those taking no more than three meals each day than in those taking at least five meals (Fábry et al., 1964). Treatment of obesity by allowing frequent small meals has previously been assessed (Gordon et al., 1963), but the results, though encouraging, are not strictly valid, as the dietary modifications were associated with the use of triiodothyronine and diuretics. A clinical trial is reported in which hospital outpatients having " refractory obesity" (Duncan et al., 1960) were treated with a diet of five 200-calorie meals each day for 12 weeks.

\section{Selection of Patients and Conduct of Trial}

Thirty-nine adult women were chosen for the study. Most were housewives and all were obese, being at least $20 \%$ overweight (United States Medico-Actuarial Investigations, 1912), but none showed clinical evidence of cardiac failure or oedema.
Five patients were mild diabetics, who on diet alone had only occasional postprandial glycosuria. All had attended the dietetic out-patient department regularly for at least the previous 12 months, during which time their attempts to adhere to prescribed subcaloric diets containing approximately 1,000 calories had met with little or no success and resulted in no

TABle I.-Relevant Data for the 35 Patients (Mean Age 54.9 Years Range 40-75) Who Completed the Study

\begin{tabular}{|c|c|c|c|}
\hline & & lb. & kg. \\
\hline 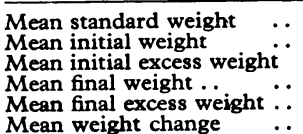 & $\begin{array}{l}\ldots \\
\because \\
\because \\
\because\end{array}$ & $\begin{array}{l}142 \cdot 0(127-171) \\
195 \cdot 1(156-303) \\
39 \cdot 7 \%(20-77 \%) \\
189 \cdot 7(145-296) \\
35 \cdot 5 \%(11-73 \%) \\
-5 \cdot 4(+2--22)\end{array}$ & $\begin{array}{c}64.4(57 \cdot 6-77 \cdot 6) \\
90 \cdot 3(70 \cdot 8-137 \cdot 4) \\
86 \cdot 0(65 \cdot 8-134 \cdot 3) \\
-2.45(+0.9--10 \cdot 0)\end{array}$ \\
\hline
\end{tabular}

significant loss of weight in the three months immediately preceding the trial. Fourteen patients had completed an earlier trial of two 500-calorie meals a day nine months previously (Seaton and Duncan, 1964), but thereafter regained weight and none had taken anorexigenic drugs for at least one year. The relevant data for the 35 patients who finished the trial are given in Table I.

* Diabetic and Dietetic Department and University Department of Therapeutics, the Royal Infirmary, Edinburgh. 